University of Wollongong

Research Online

Faculty of Engineering and Information

Faculty of Engineering and Information

Sciences - Papers: Part A

Sciences

$1-1-2014$

Retrofitting nonseismically detailed exterior beam-column joints using concrete covers together with CFRP jacket

Muhammad N. S Hadi

University of Wollongong, mhadi@uow.edu.au

Tung Minh Tran

University of Wollongong, tmt954@uowmail.edu.au

Follow this and additional works at: https://ro.uow.edu.au/eispapers

Part of the Engineering Commons, and the Science and Technology Studies Commons

Research Online is the open access institutional repository for the University of Wollongong. For further information contact the UOW Library: research-pubs@uow.edu.au 


\title{
Retrofitting nonseismically detailed exterior beam-column joints using concrete covers together with CFRP jacket
}

\author{
Abstract \\ This paper introduces a new method for retrofitting reinforced concrete (RC) exterior beamcolumn T \\ joints, using segmental circular concrete covers together with Carbon Fibre Reinforced Polymer (CFRP). \\ Two RC T connections without transverse reinforcement at the joints were cast and tested. The first \\ connection (Strengthened specimen, TS) was glued with the concrete covers around the column at the \\ joint area to modify it from a square to a circular section and then it was wrapped with CFRP to \\ strengthen its capacity. A load was first applied on the second connection (Repaired specimen, TR) to \\ cause a serious failure then it was repaired. The repair scheme of the second connection was identical to \\ the first connection. Results of testing the two connections have shown that the performances of both \\ the strengthened and the repaired connections were improved significantly. The glued concrete covers \\ worked well with the existing concrete to resist shear load. Moreover, the wrap on the modified circular \\ sections helped in increasing the effectiveness of CFRP by increasing the confinement effect on the \\ concrete and reduce the possibility of debonding of CFRP at the joints.
}

\section{Keywords}

joints, column, beam, exterior, detailed, nonseismically, retrofitting, together, jacket, covers, cfrp, concrete

Disciplines

Engineering | Science and Technology Studies

\section{Publication Details}

Hadi, M. N. S. \& Tran, T. Minh. (2014). Retrofitting nonseismically detailed exterior beam-column joints using concrete covers together with CFRP jacket. Construction and Building Materials, 63, 161-173. 
1 Retrofitting Nonseismically Detailed Exterior Beam-Column Joints Using Concrete

3 Muhammad N.S. Hadi *, Tung Minh Tran

\section{1. Introduction}

7 In reinforced concrete (RC) frames, $\mathrm{T}$ connections (exterior beam-column joints) have been

8 recognized as the weaker components when subjected to cyclic lateral loads. Severe damage

9 of a connection in general and of a $\mathrm{T}$ connection in particular may cause deterioration of the whole performance of the frame. Many RC frames were originally designed to carry only gravity loads. They lack the ductility and strength to present a global failure mechanism caused by cyclic loading conditions. These structures typically have a non-ductile reinforcement at the beam-column joint areas in terms of inadequate transverse reinforcements and/or weak-column/strong-beam philosophy of design. Therefore, strengthening of underdesigned RC T connections built in seismic areas has been a crucial requirement.

Several studies have proposed various ways to retrofit RC T connections in recent decades.

Some of the traditional techniques include epoxy repair, removal and replacement, concrete jacketing, concrete masonry unit jacketing and steel jacketing. Engindeniz et al. [1] summarized most of these techniques and concluded that they can improve the performance of the strengthened connections but have some limitations such as complicated, expensive construction and corrosion problems. A method of rehabilitation using steel straps was also introduced but this method could not fully restore the performance of the destructed RC T

\footnotetext{
* Corresponding author: Tel.: +61 24221 4762; Fax: +61 24221 3238; E-mail address: mhadi@uow.edu.au
} 
connections [2]. Externally bonded fibre reinforced polymer (FRP) was recognized as an

ideal method as it can eliminate some important limitations of other conventional strengthening methods.

Gergely et al. [3] carried out a series of 14 1/3-scale tests with the aim to improve the shear strength and ductility of RC T connections by externally bonded CFRP. They concluded that CFRP was able to improve the shear resistance as well as the ductility of RC $\mathrm{T}$ connections and the most effective fibres in the joint region is inclined at $45^{0}$ to the direction of principal planes. Antonopoulos and Triantafillou [4] tested 18 2/3 scale RC T connections in an experimental program to study the role of various parameters (reinforcement ratio; distribution of FRP; column axial load; and internal joint reinforcement). They highlighted that mechanical anchorages can significantly eliminate premature debonding of FRP to increase the effectiveness of the strengthening method. Recently, several research studies [510] have been published on the effectiveness of many different FRP retrofitting configurations for retrofitting RC beam-column connections. Gergely et al. [3] and Almusallam and Al-Salloum [11] introduced analytical models for predicting shear capacity of the FRP-strengthened beam-column connections. Tsonos [12] proposed an analytical method which highlighted the confined effect of FRP on shear performance of the retrofitted connection. Akguzel and Pampanin [13] developed an analytical model in which the principal tension stress was suggested to be the key criterion that controls the shear strength of the retrofitted joints.

It is obvious that confinement increases the performance of RC structures. Many researchers $[5,8,10,14]$ accepted that the increased confinement of joints caused by externally bonded FRP leads to the improvement in the performance of the repaired or strengthened RC beamcolumn connections subjected to cyclic lateral loads. However, in the previous studies, most of the retrofitting techniques were bonding FRP at the joints around square or rectangular 
sections of the columns and/or beams, which may give little confinement effect. In this study, in order to retrofit a RC T connection, the column of the joint was firstly modified from a square to a circular section by bonding four plain concrete covers, herein referred to as "segmental circular concrete covers", and then it was wrapped with CFRP. Details of the retrofitting method are described in the following sections.

Wrapping of CFRP around a modified circular or an identical section can effectively increase the efficiency of FRP confinement by reducing the stress concentration in the sharp corners as on a square or a rectangular section. This beneficial effect has been successfully proved by Herwig and Motavalli [15] on confining square columns using unbonded fibre-reinforced polymer wrapping and Hadi [16] on retrofitting shear failed beams. Similar results have been pointed based on the experimental studies carried out by Hadi et al. [17] on strengthening square RC columns using fibres combined with segmental circular concrete covers. Additionally, wrapping circular sections may eliminate debonding possibility, which is believed to be the key factor for the effectiveness of a strengthening method using CFRP. Based on the above results, the same technique was extended to retrofit RC $\mathrm{T}$ connections. This paper presents results of testing two RC $\mathrm{T}$ connections, one was strengthened from intact condition and the other was repaired after being partially failed, both using the proposed method. A direct comparison of the load deflection envelopes between the strengthened and the repaired connections is introduced, which shows that the proposed method is effective for strengthening and repairing RC T connections.

\section{Material and methods}

\subsection{Design and preparation of the specimens}

Two identical RC T connections were cast, one was strengthened and denoted as Specimen TS (Strengthened T connection). For the second, Specimen TR (Repaired T connection), a load was firstly applied on the beam to cause a serious failure at the joint, and then the 
connection was repaired using the same technique of Specimen TS. The design of the connections is typical for gravity load frames built in the 1970s. A $200 \mathrm{~mm}$ square column and a $200 \times 300 \mathrm{~mm}$ rectangular cross section beam, which was rounded with a radius $r=20$ $\mathrm{mm}$ at its four corners, was selected. The column length was $2.80 \mathrm{~m}$ and the beam length was $1.40 \mathrm{~m}$ from the column face. Two sets of four N12 bars (12 mm deformed bars with 500 MPa nominal tensile strength) were chosen as negative and positive longitudinal reinforcement of the beams. These bars were anchored in the joints by 90-degree standard hooks, which were located within $50 \mathrm{~mm}$ from the back face of the column. The hook tails length were $230 \mathrm{~mm}$, facing into the joint. R10 (10 mm plain bars with $250 \mathrm{MPa}$ nominal tensile strength) stirrups, spaced at $75 \mathrm{~mm}$ centres for $650 \mathrm{~mm}$ from the column face then at $150 \mathrm{~mm}$ centres for $450 \mathrm{~mm}$, ending at $83 \mathrm{~mm}$ centres for $300 \mathrm{~mm}$ from the free end of the beam were used as transverse reinforcement of the beam. Six N16 bars were placed as the longitudinal column reinforcement and R10 ties, spaced at $100 \mathrm{~mm}$ centres, were used as transverse reinforcement. No transverse reinforcement was installed in the beam-column joint. In all beams and columns, the concrete cover was $20 \mathrm{~mm}$, the first tie of beams and columns was placed at $50 \mathrm{~mm}$ from the face of columns and beams, respectively. Details of the reinforced design and dimensions of the specimens are shown in Fig. 1. From this figure it can be seen that the transverse beams and slab are not included in the specimens. In practice, this form of beam-column connection can be seen in RC bridges or in some RC frames of buildings in which these elements are not connected directly to the beam-column joint but are connected to the main beam at a certain distance from the column face, for example when there are openings in slabs or when the edge-side columns of the building are not connected directly to the slab and the transverse beams. It is noted that under seismic load this type of exterior connection is weaker than joints where transverse beams and slab are connected because the existence of these elements at the joint location improve the joint shear 
strength. Furthermore, similar exterior connections have also been strengthened and tested recently by many authors, for example [18-20].

The concrete used in the experiments was normal strength concrete supplied by a local supplier, with a $10 \mathrm{~mm}$ maximum aggregate size and a $120 \mathrm{~mm}$ slump. Both specimens were cast horizontally rather than vertically as in a real building construction. All the formworks were made from plywood and were screwed together with timber and L-section bars of steel. Specially shaped foams were bonded to the formworks to generate round corners for the beams and for the segmental circular concrete covers. The images of the formworks before casting are shown in Fig. 2. Twenty four hours after casting, the specimens were cured by covering with moist hessian, which was kept wet by watering at 12 hour intervals. After two weeks of curing, Specimen TR was removed from the formworks then it was stored in the laboratory for preparing the test. The formworks were used again for casting Specimen TS. The curing procedure for Specimen TS was similar to Specimen TR.

Tensile tests were performed in accordance with AS 1391 [21] on three $250 \mathrm{~mm}$ long coupon specimens for each different diameter steel bars. The yield strength was calculated by averaging the results of each set of three specimens. The average yield stresses of the N16, N12 and R10 were 550, 551 and $322 \mathrm{MPa}$, while their average ultimate stresses were 647, 654 and $485 \mathrm{MPa}$, respectively.

117 Compression tests were performed in accordance with AS 1012.09 [22] on three $100 \mathrm{~mm}$ diameter and $200 \mathrm{~mm}$ high cylinder samples for each batch of concrete. The average compressive strength of the concrete in Specimen TS and the segmental circular covers at testing time of the connection was $50 \mathrm{MPa}$. The average compressive strength at testing time for Specimen TR was $49 \mathrm{MPa}$. 
122 With the above designs, the 90-degree hooks at the end of the longitudinal beam bars had a straight extension at the tail of the hooks of length less than the required value given by ACI352R [23]. The ratio of the theoretical flexural strength of the columns to that of the beam was $M_{R}=1.49$, calculated using the design material properties and a strength reduction factor of unity. ACI-352R [23] specifies that the maximum allowable joint shear stress of a beamcolumn joint is $v_{j h}=\gamma \sqrt{f_{c}^{\prime}} M P a$, where $\gamma$ is joint shear stress factor, $f_{c}^{\prime}$ is the concrete compressive strength. For the case of an exterior beam-column connection, which is seismically detailed, values $M_{R} \geq 1.2$ and $\gamma \leq 1$ are required. In the examined joints, the joint shear stresses calculated using the design material properties were $1.11 \sqrt{f_{c}^{\prime}} M P a$ and the joints were also not seismically detailed. Thus, the beam connections of the original specimens could be expected to fail in joint shear mode. In fact, as expected, Specimen TR experienced a serious damage in joint shear failure mode when a load was applied to cause a $53 \mathrm{~mm}$ deflection at the beam end (1100 $\mathrm{mm}$ from the beam-column interface).

\subsection{Experimental setup}

A testing frame was used to test the specimens. The experimental setup is shown in Fig. 3 (a).

The ends of the column were connected to the frame by hinge supports. No compression load was applied on the columns to evaluate the worst-case circumstance for a $\mathrm{T}$ connection as mentioned by Quintero and Wight [24]. A $600 \mathrm{kN}$ hydraulic actuator was used to apply a vertical frequency cyclic loading onto the beam by slowly displacing the beam's free end to create bending moment within the RC connection. A $600 \mathrm{kN}$ load cell was fixed on top of the hydraulic jack to measure the applied load. The loads were applied at a distance of $1100 \mathrm{~mm}$ from the beam-column interface. The hydraulic jack was set to keep the deflection rate of 5 mm per minute. The cyclic loading history is shown in Fig. 3 (b). The amplitudes of the peaks in the displacement history were ranged between $10 \mathrm{~mm}$ and $90 \mathrm{~mm}$ with $10 \mathrm{~mm}$ steps. 
146 The deflection of the beam end was measured by a LVDT which was placed at the bottom

147 face of the beam at a distance of $1100 \mathrm{~mm}$ from the beam-column interface. In order to measure the rotation of the beam and the column, one inclinometer and two LVDs were used.

The inclinometer was placed on the beam at the beam-column interface and the LVDTs were placed on the column at distances of $300 \mathrm{~mm}$ from the top and bottom faces of the beam (Fig. 3 a).

In order to examine the behaviour of the steel reinforcement and CFRP during the tests, a total of 37 strain gauges were installed on each specimen. The location of the strain gauges on a specimen is shown in Fig. 4. Five strain gauges (Strain gauges 1, 2, 3, 4, and 9) were installed on the column reinforcement at the level of the lower face of the beam. The other five (Strain gauges 5, 6, 7, 8, and 10) were installed at the level of upper surface of the beam. Four strain gauges (Strain gauges 11-14) were installed at the the top and bottom reinforcement of the beam, at the location of beam-column interface.

Three rows of strain gauges, 4 strain gauges at each row, were installed on the CFRP at the joint, parallel to the $x-y$ plane (refer to Fig. 4). The first row located at a distance of $40 \mathrm{~mm}$ below the top of the beam. Starting from the extension of axis $o x$, four strain gauges were installed at $45^{\circ}$ angles. An identical arrangement was used for the installation of strain gauges on the second and the third rows, which were located at distances 150 and $260 \mathrm{~mm}$, respectively, from the top of the beam. On the front face of the beam, three rows, 3 strain gauges each rows, were installed on the CFRP at distances of 50, 150, $200 \mathrm{~mm}$ from the beam-column interface. The first and the second rows were parallel to $O z$ axis while the third row was parallel to $O x$ axis. On the top of the beam, two strain gauges were placed parallel to the $x-y$ plane at distances of 50 and $100 \mathrm{~mm}$ from the column face. 
Three $900 \mathrm{~mm}$ long and two $300 \mathrm{~mm}$ long segmental circular concrete covers, which were cast at the same time of casting Specimen TS, were used to modify the column at the joint from a square to a circular section. The cross section of these segments is shown in Fig. 5. Firstly, the surfaces of the specimen around the beam-column joint area and of the segmental circular concrete covers were ground using an electric grinder to ensure smooth contact surfaces. After that, they were cleaned by using air blasting before bonding and wrapping with CFRP.

Unidirectional Carbon fibre reinforced polymer sheets were used to strengthen the $\mathrm{T}$ connection. The type of fibre was Carbon-uni-fabric with nominal fibre thickness $t_{f}=0.167$ mm and the applied resin was a mixture of epoxy resin R105 and hardener R206 at weight ratio of 5:1. The properties of CFRP were determined by CFRP coupon tests conducted in accordance with ASTM D7565 [25]. Five 25 mm wide coupon samples containing two individual layers of CFRP on each sample were made and tested. Results of the CFRP coupons test are shown in Table 1.

Strengthening of the connection included six steps. Fig. 5 shows an illustration of the specimen after the completion of each step in the strengthening process. In the first step, three $900 \mathrm{~mm}$ segmental circular concrete covers were bonded onto three faces of the column using a mix of epoxy resin and 20\% thickener. Details of the bonding technique can be seen in Tran et al. [26]. The strengthening process was continued in the second step by wrapping two 222 mm wide CFRP vertical layers onto two opposite faces of the segmental circular concrete covers for a distance of $900 \mathrm{~mm}$, parallel to the column longitudinal axis. This CFRP application aims at increasing the flexural capacity of the columns near the joint. In the next step, two CFRP layers were wrapped around the column for the width of the joint (300 mm). These two layers were intended to help in improving the shear strength of the joint and were extended $300 \mathrm{~mm}$ into the length of the beam for anchorage as well as for improving the 
flexural capacity of the beam near the joint. In the fourth step, two layers of $200 \mathrm{~mm}$ wide CFRP were wrapped around the beam of the specimen as close as possible to the face of the column. Next, two more layers of $100 \mathrm{~mm}$ wide CFRP were wrapped around the beam, once again as close as possible to the column face to provide further anchorage. The overlap of the wrapped CFRPs was calculated similar to the calculation for the bonded Tab Length required by ASTM D3039 [27]. For easy application, an overlap distance of $100 \mathrm{~mm}$, which is longer than the calculated values, were applied for all the wrapped CFRPs. In the fifth step, two 300 mm long segmental circular concrete covers were bonded onto the face of the column adjacent to the beam using a mix of epoxy resin and a thickener as was done in the first step. In the final step, two CFRP layers (300 mm wide) were wrapped around the modified column to confine the columns and to anchor the vertical CFRPs, both above and below the beam.

\subsection{Repairing Specimen TR}

Fifty-six days after casting, Specimen TR was put in the loading frame, the ends of the column were fixed by the hinge supports and the end of the beam was connected to a hydraulic actuator. A load was applied to cause a $53 \mathrm{~mm}$ vertical deflection at the beam free end to cause a serious damage on the joint. The actuator-beam connection was then removed and the free end of the beam was recovered without any load application up to a $25 \mathrm{~mm}$ residual deflection. In order to level the beam, the hydraulic actuator and the beam's free end were connected again and the beam's free end was pushed up to a deflection of $-20 \mathrm{~mm}$. After removing the load, the beam's free end was naturally recovered to its original position before the application of the load. The failed joint was then removed from the frame for repair.

The crack patterns of the failed joint before repair are shown in Fig. 6. Diagonal cracks in the joint core region were developed and opened widely. The widest diagonal crack was measured to be approximately $3 \mathrm{~mm}$. Bond-splitting cracks along the column longitudinal 
bars, extended approximately $320 \mathrm{~mm}$ and $100 \mathrm{~mm}$ from the top and bottom faces of the beam, respectively (Fig. 6 a-c). The bond-splitting cracks opened widely and connected with the joint diagonal tension cracks. Small visible beam and column flexural cracks were found at the top corner of the beam-column joint, while the concrete at the bottom corner began to crush (Fig. 6 d). No obvious flexural cracks were observed at the upper and lower parts of the column. Clyde et al. [28] characterized five failure levels of beam-column connections. Based on this study, it can be classified that the damage of Specimen TR was at the fifth of the five failure levels. This damage level corresponds to full development of the failure mechanism and deterioration of the joint shear strength, thus, it can be confirmed that the joint of Specimen TR was seriously damaged.

Before repair, Specimen TR was ground using an electronic grinder to ensure smooth contact surfaces and then cleaned by using air blasting. The back of the column at the joint, which was still not smooth due to expansion of the cracked concrete, was flattened by a $3 \mathrm{~mm}$ thick layer of high strength plaster. In the next stage, the cracks at the joint were filled with epoxy resin. Epoxy resin was dumped firstly on the front face of the joint to allow it to leak freely due to its own weight into the cracks. When leaking into the cracks, epoxy was supplied and dumped again on joint surface until no more epoxy resin could leak. As epoxy leaks slowly, the epoxy filling process was carried out slowly (the filling process lasted 8 hours) to ensure that most of the cracks were fully filled with epoxy resin. After the epoxy on the front surface was cured, the connection was rotated $180^{\circ}$ to fill epoxy for the back surface. The epoxy filling process on the back surface was identical to that of the front one. Fig. 7 shows an illustration of the joint after filling epoxy. After epoxy was filled, segmental circular concrete covers were glued to modify the column from square to circular section and the joint was then wrapped with CFRP. The process of gluing the segmental circular concrete covers and 
wrapping CFRP for Specimen TR included six steps, exactly the same as those used for strengthening Specimen TS.

\section{Results}

247

\subsection{Behaviour of the specimens}

248

\subsubsection{Specimen TS}

The measured story shear force $P$ versus drift $R$ of the strengthened Specimen TS is shown in

Fig. 8 (a), in which the drift $R$ is determined as ratio between the beam tip deflection $\Delta$ and the beam length $L$ [28-32]. The theoretical loads associated with the nominal flexural capacity of the beam without the contribution of CFRP, which were calculated following the design requirements of AS 3600 [33] using the measured concrete and steel yield strength, are $P_{y}= \pm 56.4 \mathrm{kN}$. In the first cycle of loading $(R= \pm 0.83 \%)$, no visible cracks were observed in both the column and the beam outside the strengthening area. In the second cycle $(R= \pm 1.67 \%)$, flexural cracks were initiated in both column and beam close to the strengthened area. In the third cycle of loading ( $R= \pm 2.5 \%)$, at a load higher than $60 \mathrm{kN}$, crack sounds which may have been caused by debonding and/or rupture of CFRP were recorded. At the end of this loading cycle when the load was higher than $70 \mathrm{kN}$, the top and bottom parts of the horizontal CFRP layers around the joint started to break along the vertical lines at the beam-column interface. Debonding developed slowly in loading cycles 4-7 until all horizontal layers of CFRP at the beam-column interface were ruptured. The debonding area was eliminated effectively by the transverse anchorage CFRP layers. Following the rupture of horizontal CFRP layers around the joint, the beam flexural cracks were developed and opened wide at the beam-column interface. The development of the debonding area and the rupture of the horizontal CFRP at the loading cycles from the third to the seventh are shown in Fig. 9. 
The measured strains of CFRPs showed that CFRPs were under tension during the test and the concrete at the joint was affected by relatively high confinement stress. They also showed that the horizontal CFRP near the back of the column had smaller strains than the horizontal CFRP near the beam-column interface. At the peak of the third loading cycle, when the top of the horizontal CFRP layers started to break along a vertical line at the beam-column interface, Strain Gauges 26 recorded a maximum strain of $0.58 \%$. This value was approximately $32.4 \%$ of the CFRP ultimate strain measured from the coupon tests. At the peak of the fourth loading cycle, the average strain recorded from Strain Gauges 23-26 (see Fig. 4) was approximately $0.37 \%$, while that of Strain Gauges $19-22$ was $0.24 \%$. In the following loading cycles, due to breaking of CFRP around the joint, the strain of the CFRP at the location of Strain Gauges 26, 22 and 18 reduced to values close to zero. However, the strain of CFRP at the centre of the joint (Strain Gauge 21) still maintained at a high level ( $0.34 \%$ and $0.39 \%$ at the peaks of the fourth and the fifth loading cycles, respectively) before decreasing slowly in the following loading cycles. This indicated that although the anchorage CFRP around the beam was ineffective in the last loading cycles (due to breaking of the horizontal CFRP layers), the horizontal CFRP still contributed to resist the joint shear force and thus delaying the failure of the joint. Whereas, the strain gauges installed on the column reinforcement recorded values of below $0.2 \%$ during the nine loading cycles. It means that column reinforcement responded elastically. The strain gauges on the beam reinforcement recorded higher strains. At the peak load of the $3^{\text {rd }}$ loading cycle, Strain Gauges 13 and 14 (see Fig. 4) recorded an average tension strains of $0.46 \%, 15 \%$ higher than the yield strain of beam reinforcement measured from the coupon test.

The average maximun load $P_{\text {Maxl }}=80.7 \mathrm{kN}$ was recorded at the end of the $4^{\text {th }}$ loading cycle corresponding to a drift of $3.33 \%$. After reaching the maximum load, the peak loads of the 
latter loading cycles reduced slowly to an average value of $50.9 \mathrm{kN}$, a $37 \%$ reduction, at the

$293 \quad 9^{\text {th }}$ loading cycle.

294 After testing, Specimen TS was removed from the loading frame and the CFRP at the joint was peeled to observe the cracking patterns of the joint inside the CFRP jacket. Fig. 10 shows the cracking patterns of the joint at the end of testing. Fig. 10 (a) shows the joint after small concrete crushing fragments were removed using air blasting, Fig. 10 (b) shows an illustration of the joint after large concrete crushing fragments were manually removed, and Fig. 10 (c) is its image when the loose concrete was removed. From the figures, it can be seen that flexural cracks occurred at the top and bottom of the beam-column corners and further developed to connect with the diagonal cracks of the joint. Other cracks were caused by the application of tension and compression to the concrete at the joint. The diagonal cracks at the joint developed stronger and wider at areas close to the beam -column interface while smaller cracks occurred at areas near the backside of the column. No considerable cracks were observed on the beam and the column outside the joint area and on the segmental concrete cover at the backside of the column. Interestingly, most of the cracks developed perpendicular to the glued surfaces and passing through the existence and the concrete cover. Cracks that tended to separate the concrete covers along the glued surfaces were not recorded. Fig. 10 (d) shows a typical crushing concrete fragments being removed from the crushing area. The bond between the existence and the glued concrete was maintained. The above findings indicated that the concrete covers worked very well with the existing concrete to resist the load.

\subsubsection{Specimen $T R$}

The measured story shear force $P$ versus drift $R$ of the repaired Specimen TR is shown in Fig.

8 (b). Similar to Specimen TS, the theoretical loads associated with the nominal flexural capacity of the beam without the contribution of CFRP of Specimen TR are approximately 

approximate $10 \%$ reduction of load was recorded. The average maximum load of Specimen TR was $P_{\text {Max } 2}=72.4 \mathrm{kN}$ which occurred at a drift of $3.3 \%$ (the fourth loading cycle). The debonding area, the rupture process and the strain of CFRP jacket were developed similar to that of Specimen TS. The significant difference between the responses of the two specimens is that, in the $7^{\text {th }}, 8^{\text {th }}$ and $9^{\text {th }}$ loading cycles, the peak loads fell rapidly on Specimen TR while they reduced slowly on Specimen TR.

In Specimen TR, the cracking patterns inside the CFRP jacket show that flexural cracks were developed and connected with diagonal cracks. Fig. 11 (a) and (b) show the crack patterns of the joint before and after removing the crushed concrete. It can be seen that crushing occurred mainly close to the beam-column interface, outside this area, only small cracks appeared. The concrete at the back of the column was still intact and no visible cracks were observed.

\subsection{Shear strength and Stiffness}

The stiffness of the whole specimen depends on the stiffness of the beam, the column and the joint. The stiffness of the whole Specimens TS and TR can be gleaned from the graphs in Fig.

8. However, only the joint area of the specimens TS and TR was retrofitted, thus, in this part, the joint stiffness was considered in order to evaluate the efficiency of the retrofitted method. Priestley [34] suggested a model to predict the stiffness and shear capacity of nonseismically detailed RC T connection. Following Priestley's model [34], the story shear force $P$ versus joint rotation relation of an identical RC T connection was calculated and is shown in Fig. 12 (a). This relation recorded from testing Specimens TS and TR is also attached in this figure for easy comparison. Additionally, the stiffness of the joints (the ratio between story shear force $\mathrm{P}$ and joint rotation) was calculated and the stiffness ratio between the Specimens TS and TR on every negative loading cycle is shown in Fig. 12 (b). Using Priestley’s model [34], a peak load of $31.4 \mathrm{kN}$ reached at joint rotation approximately 0.07 was determined for 
the identical connection. Comparing with this value, the strength increases approximately 157\% (from $31.4 \mathrm{kN}$ to $80.7 \mathrm{kN}$ ) for Specimen TS and 131\% for Specimen TR (from $31.4 \mathrm{kN}$ to $72.4 \mathrm{kN}$ ). It is noted that due to the prohibitive cost, no as-built specimen was tested in this study. Thus, these improvements in the joint shear strength are just compared with the theory results of an identical as-built specimen. However, the lack of the as-built specimen in this case is believed not to cause considerable influence on the evaluation of the effectiveness of the proposed retrofitting method. This is because the behaviour of the as-built exterior connections has been extensively studied and the accurate theoretical predictions of the joint shear behaviour in general and Priestley's model [34] in particular has been verified and widely accepted by the research community. In addition, the very impressive results reached from the proposed method compared to the existing methods are also the reason for supporting the efficiency of the proposed method. It is because the summary of the past research studies on FRP strengthening beam-column connections $[35,36]$ showed that the maximum improvement in the joint shear strength of the existing FRP method was only 85\%, a very low value when compared with the figures reached from this retrofitting method.

Fig. 12 (a) shows that although the joints' shear strength of Specimens TS and TR increased significantly, their initial joint stiffness was not noticeably improved. Whereas, Fig. 12 (b) illustrates the difference in the joint stiffness of Specimens TS and TR, especially at the last three loading cycles. From this figure it is easy to realize that the stiffness is basically identical for the joints of Specimens TS and TR at the first six loading cycles but significantly higher for Specimen TS at the last three loading cycles. The TS to TR joint stiffness ratio increased slowly from 0.84 to 1.42 for the first six loading cycles but it jumped rapidly to 1.88 in the seventh cycles and reached a relatively high value of 2.13 at the last cycle. These differences may be caused by the deterioration of the concrete and the reinforcement-concrete bond due to the prior failure because, at these stages, the horizontal CFRP at the beam- 
column interface were ruptured and the flexural capacity of the beam was contributed only by the reinforcement. It seems that the filled epoxy only partly restored the bonding condition between the beam reinforcement and the concrete. This assumption was strongly proved by the evidence that the strain of beam longitudinal reinforcement in Specimen TS was higher than that of Specimen TR at the same deflections. For example, at the peak of the third loading cycle, Strain Gauges 13, 14 on Specimen TS recorded an average strain of $0.46 \%$ while a value of $0.21 \%$ was recorded in the case of Specimen TR at the same stage.

\subsection{Displacement ductility}

One of the main targets of the retrofitting method is improving the ductility performance of the joints. In order to evaluate the improvement in ductility of the two retrofitted connections, the displacement ductility index $\mu$ suggested by Li et al. [37] was used. The definition of displacement ductility index is shown in Equation (1):

$$
\mu=\frac{\Delta_{u}}{\Delta_{y}}
$$

where $\Delta_{u}$ is the deflection corresponding to a $10 \%$ strength degradation of the maximum strength $\left(P_{\text {Max }}\right)$ of the specimen and the yield deflection $\Delta_{y}$ is the deflection corresponding to the first yield of the longitudinal beam reinforcement. In the investigated specimens yield deflections $\Delta_{y 1}=18 \mathrm{~mm}$ for Specimen TS and $\Delta_{y 2}=22 \mathrm{~mm}$ for Specimen TR were determined corresponding to the yield load $P_{y}$ of the beam. The deflections $\Delta_{u 1}=65 \mathrm{~mm}$ for Specimen TS and $\Delta_{u 2}=58 \mathrm{~mm}$ for Specimen TR are estimated as the deflections corresponding to $10 \%$ strength degradation. Calculating using Equation (1), the displacement ductility indexes of 3.6 and 2.6 were reached for Specimens TS and TR, respectively. 
The dissipated energy of a retrofitted specimen, which is defined as the area under the load versus deflection is one of the most important criteria for the behaviour of $\mathrm{T}$ connections under cyclic load. The computed energy dissipation at every loading cycle for Specimen TS and TR is shown in Fig. 13. At the first loading cycle, energy dissipation of both specimens is similar. However, at latter loading cycles the energy dissipation of Specimen TS is higher than that of Specimen TR from 15 to 27\%. Similar to stiffness and peak loads, most differences in energy dissipation occurred at the last three loading cycles.

\section{Discussion}

\subsection{Shear capacity of the connections}

In the retrofitting method, the flexural capacity of the beams increased by the application of horizontal CFRP on the beams close to the columns. The flexural strength provided by the CFRP and steel reinforcement, can be calculated using section analysis as presented in Fig. 14. From this figure, the increased flexural strength contributed by CFRP can be calculated as:

$$
M_{C F R P}=T_{C F R P} d_{f}
$$

where $T_{C F R P}=\varepsilon_{f} A_{f} E_{f}$ is the maximum tensile force that can be carried by the horizontal CFRP layers along the beam; $\varepsilon_{f}=0.5 \varepsilon_{f, \operatorname{Max}}$ is the average tensile strain of CFRP; $\varepsilon_{f, \operatorname{Max}}$ is the rupture strain of the horizontal CFRP at the beam-column interface; $E_{f}$ (238 GPa) is the elastic modulus of CFRP fibre determined from coupon tests; $d_{f}$ is the distance from CFRP tension force to the centre of the compressive stress block; $A_{f}$ is the cross sectional area of the tensile fibre wrapped along the beam $\left(A_{f}=2 n\left(h_{b}-c\right) t_{f}\right) ; h_{b}$ is the beam height; $n=2$ is the number of horizontal CFRP layers and $c$ is the distance from the neutral axis to the beam top face (Fig. 
411 14). The determination of $c$ is based on the equilibrium of the tensile forces $\left(T_{b}+T_{C F R P}\right)$ and 412 the compressive forces $\left(\varepsilon_{s c} A_{s} E_{s}+\alpha f_{c}^{\prime} A_{c}\right)$.

413 The nominal moment strength $M_{n} \approx \alpha_{o} M_{y}$ ( $M_{y}$ is beam moment strength corresponding to yield of beam reinforcement calculated following the design requirements of AS 3600-2009 and $\alpha_{o}=1.17$ is the ratio between the ultimate strength and yield strength of beam reinforcement) of Specimens TR and TS without contribution of CFRP was approximately $72.7 \mathrm{kN}-\mathrm{m}$, corresponding to beam tip load $P_{n}=66.1 \mathrm{kN}$. Table 2 shows the calculated beam tip load of Specimens TS and TR corresponding to their beam flexural strengths. In the calculation the CFRP rupture strain, $\varepsilon_{f, \mathrm{Max}}=0.58 \%$ (about one third of its rupture strain measured from the coupon tests) recorded by Strain Gauge 26 was assumed. From the table, it can be seen that the predicted and the measured beam tip loads for Specimen TS are close; the difference is only $1.8 \%$. However, the measured beam tip load for Specimen TR was approximately $10.4 \%$ lower than the predicted one. This significant error could be caused by the assumption in the calculation in which the concrete and the reinforcement in Specimen TR did not deteriorate. The increase in beam moment strength calculated from Equation 2 for the retrofitted Specimens TS and TR was approximately $22.5 \mathrm{kN}-\mathrm{m}$, an increment of 30.9\%.

427 For the original specimen, the shear strength of the joints was estimated based on Priestley's model [34] by using Equation 3

$$
V_{n}=\gamma \sqrt{f_{c}^{\prime}} b_{j} h_{c}
$$

where $\gamma$ is a factor, in the case of the examined RC T connections, $\gamma=0.42$ was suggested by Priestley [34], $b_{j} h_{c}$ is the area of the column at the joint. The total shear force in the joint can be calculated using Equation 4 as the shear carried through the column and the joint resulting from beam tensile reinforcement 
435 where $T_{b}=\alpha_{o} A_{s} f_{y}$ is the tensile force in the beam longitudinal reinforcement;

$436 V_{c}=\frac{P_{n}\left(L+0.5 h_{c}\right)}{H} \quad$ is the shear force in the column; $L=1100 \mathrm{~mm}$ is the distance from the

437 location of applied load P to the beam-column interface; $H=2200 \mathrm{~mm}$ is the distance from

438 the two hinge supports of the columns; $h_{c}=200 \mathrm{~mm}$ is the column section height.

439 For the CFRP retrofitted specimens, the joint shear force corresponding to the maximum

440 beam flexural capacity can be calculated using Equation 5 assuming that the tensile force in

441 the beam longitudinal reinforcement $\left(T_{b}\right)$ did not change in the retrofitted specimens.

$$
V_{\text {jh,retrofitted }}=T_{b}+T_{C F R P}-V_{c}
$$

443 As proposed by Tsonos [38], the shear capacities of the retrofitted columns and beam-column 444 joints can be calculated as follows using Equation 6:

$$
V_{R d}=V_{c d}+V_{w d}+V_{C F R P}
$$

446 where $V_{c d}=0.525 A_{j}\left(f_{c}^{\prime}\right)^{2 / 3}$ is the shear capacity of the concrete (in this study the glued concrete covers increased the volume of the joint thus the effective joint shear area increased

448 from $A_{j}=0.2 \times 0.2 \mathrm{~m}=0.04 \mathrm{~m}^{2}$ in the original connections to $A_{j}=3.14 \times 0.282^{2} / 4=0.0628 \mathrm{~m}^{2}$ 449 in the retrofitted ones); $V_{w d}$ is the shear carried by the web reinforcement (in this study $V_{w d}=$ 4500 as no web was installed at the beam-column joints) and $V_{C F R P}$ is the CFRPs contribution to 451 shear capacity calculated according to Tsonos [34] as:

$$
V_{C F R P}=0.9 \varepsilon_{f, e} E_{f} \rho_{f} A_{j}
$$


453 where $\varepsilon_{f, e}=\min \left[0.17 \varepsilon_{f u}\left(\frac{\left(f_{c}^{\prime}\right)^{2 / 3}}{E_{f} \rho_{f}}\right)^{0.3}, 0.006\right], \rho_{f}=4 n t_{f} / D$ is the CFRPs reinforcement

454 ratio, $\mathrm{D}=282 \mathrm{~mm}$ is the diameter of the modified column.

455 Table 3 presents a summary of the calculated parameters for the original and the retrofitted 456 specimens. It is noted that some numbers in Columns 3 and 4 of the table are identical. This 457 is because these numbers were calculated based on the actual material properties which were very close for Specimens TS and TR. From the table, it can be seen that the joint shear forces in the original joint are much larger than their shear strengths predicted from Priestley's model [34]. This explains why the original specimen experienced a serious shear failure at the joint (Fig. 6). Joint shear forces were calculated based on the assumption that the beams reach their flexural strengths when beam reinforcement reaches its maximum strength at the beam-column interface. Shear forces in the retrofitted joints are much higher than shear forces and shear strengths in the original joint indicating that the retrofitting method significantly increases the shear strength of the joints. Moreover, the failure of the specimens was changed from a brittle mode initiated by joint shear failure (Fig. 6) to a more ductile failure mode (Figs. 9, 10) initiated by beam flexural failures. The failure mechanism of the retrofitted specimens is explainable as their shear strengths predicted from Equation 6 is significantly higher than their shear forces calculated from Equation 5. Therefore, flexural failure of the beam might shift far from the beam-column interface if the stiffness of CFRP

471 along the beam was increased so that rupture of CFRP due to beam flexural could not start at 472 the beam-column interface.

\subsection{Failure of the specimens}

474 From the above analysis, the differences in cracking patterns, loading responds and energy dissipation of Specimens TS and TR may be explained as follows: 
476 At the first three loading cycles when CFRP jackets were not debonded nor ruptured, the

477 concrete at the joints was well confined, the beam reinforcement and the horizontal CFRP

478 layers at the joints worked together to resist beam flexural moments and thus the shear loads

479 increased gradually with rotation of both joints. An approximately $10 \%$ lower loading of

480 Specimen TR at the positive side may have been caused by the deterioration and yielding of the beam upper longitudinal reinforcement before it was repaired.

At the next three loading cycles, rupturing of the horizontal CFRP layers around the joints was initiated and developed. This rupturing process led to the reductions in both the CFRP confinement of the concrete at the joints and the flexural capacity of the beam close to the column. Therefore, the shear loads gradually reduced together with the CFRP rupture. The slight increase of peak loads from the $3^{\text {rd }}$ and $4^{\text {th }}$ loading cycles would be caused by the hardening of beam reinforcement. At the $3^{\text {rd }}$ to $6^{\text {th }}$ loading cycles, beam flexural cracks were developed rapidly because of the yield of beam reinforcement. Diagonal cracks caused by tension and compression of the concrete at the joint would have developed together with beam flexural cracks. However, as the transverse CFRP worked efficiently, the deponding possibility was eliminated. Therefore, confinement effect could be still maintained on the concrete at the joint. This effect helped delaying the development of diagional cracks.

At the last three loading cycles when horizontal CFRP layers around the joints were completely ruptured, the peak shear loads reduced rapidly of both joints as the beam reinforcement in both connections were deteriorated. The more reduction occurred on Specimen TR because the beam reinforcement and the concrete-reinforcement bond in Specimen TR could be more deteriorated. This explains why, at the end of the tests; the beam flexural cracks in Specimen TR were wider than that of Specimen TS (refer to Figs. 10 (c) and $11 \mathrm{~b}$ ). Moreover, at these stages, because the concrete close to the beam-column interface was not confined due to CFRP rupturing, the diagonal cracks could develop rapidly and fully 
connect with the beam flexural cracks. At the areas close to the beam-column interface,

502

503

504

505

506

507

508

509

510

511

512

513

514

515

516

517

518

519

520

521

522

523

524 diagonal cracks were observed to be wider and more serious on Specimen TS (refer to Figs. 10 and 11) as it carried higher load than Specimen TR. At the areas close to the back of the column of both joints, as the concrete was still well confined by CFRP (no rupture or debonding occurred at these areas), thus no serious cracks were observed.

Due to the prohibitive cost, only two specimens were tested in this study. However, from the above analysis, it can be seen that the behaviour of the tested specimens coincided very well with all the measured results including the lateral load, the strain of reinforcement and of CFRP, the joint stiffness and the joints' failures inside the CFRP jackets. These facts indicate that the test results of Specimens TS and TR were consistent. In addition, the very impressive results reached from the proposed method compared to the existing methods is another reason supporting the point that the number of the tested specimens in this study is adequate for validating qualitatively the effectiveness of the proposed retrofitting method. Further studies to quantify separately the contribution of the CFRP and the concrete covers on the joint shear performance and an extensive experimental program about this retrofitting method are suggested for future studies.

\section{Conclusions}

Based on the experimental results, the following conclusions can be drawn:

1. For both the strengthened Specimen TS and the repaired Specimen TR the performance of the joints was significantly higher than that of the theoretical calculation on an identical connection.

2. The glued segmental circular concrete covers not only help increase the effectiveness of CFRP but also worked well together with the existing concrete at the joint to resist shear load. 
3. The wrapped CFRPs on the modified circular section reduce the debonding possibility of the CFRPs from the concrete surface. Debonding just occurred in a limited area near the beam-column interface and failure occurred followed by the rupture of the horizontal CFRPs around the joints. Therefore, better performance would be gained when the stiffness of the horizontal CFRPs around the joints were increased.

4. The efficiency of the CFRPs around the joints, which is the ratio of the rupture strain of CFRPs at the joints $\left(\varepsilon_{f}=0.58 \%\right)$ and at the flat coupon tests $\left(\varepsilon_{f u}=1.8 \%\right)$, reached a value of $32.4 \%$.

5. The performance of Specimen TR is lower (approximately $10 \%$ in maximum shear load, and 20\% in energy dissipation) than Specimen TS. The reason for the lower performance of Specimen TR could be the yield of the beam longitudinal reinforcement and the deterioration of the cracked concrete. The filled epoxy in the cracks of Specimen TR could not fully restore the physical properties of the concrete and the reinforcement especially the concrete-reinforcement bond.

Finally, it can be concluded that the experimental program of this study showed that the proposed method of strengthening and repair $\mathrm{T}$ connections is impressive and can be considered for retrofitting RC T connections.

\section{ACKNOWLEDGEMENTS}

The authors would like to acknowledge the contributions of Mr Bartek Matuszkiewicz, who contributed to the laboratory works; Mr Ian Bridge, Senior Technical Officer of the Smart Engineering Laboratory, who was the main technical officer of this study and Mr Alan Grant, Senior Technical Officer, who calibrated related equipment. Additionally, the second author would like to acknowledge the Vietnamese Government and the University of Wollongong for supporting his $\mathrm{PhD}$ scholarship. 
550 [1] Engindeniz M, Kahn LF, Zureick AH. Repair and strengthening of reinforced concrete beam-column joints: State of the art. ACI Struct J 2005; 102: 187-97.

552 [2] Hadi MNS. Rehabilitating destructed reinforced concrete t connections by steel straps. Constr Build Mater 2011; 25: 851-58.

554 [3] Gergely J, Pantelides CP, Reaveley LD. Shear strengthening of RCT-joints using CFRP composites. J Compos Constr 2000; 4: 56-64.

[4] Antonopoulos CP,Triantafillou TC. Experimental investigation of FRP-strengthened RC beam-column joints. J Compos Constr 2003; 7: 39-49.

[5] Ghobarah A, Said A. Seismic rehabilitation of beam-column joints using FRP laminates. Earthq Eng 2001; 5: 113-29.

Singh V, Bansal PP, Kumar M, Kaushik SK. Experimental studies on strength and ductility of CFRP jacketed reinforced concrete beam-column joints. Constr Build Mater 2014; 55: 194-01.

[7] Realfonzo R, Napoli A, Pinilla JGR. Cyclic behavior of RC beam-column joints strengthened with FRP systems. Constr Build Mater 2014; 54: 282-97.

[8] Al-Salloum YA, Almusallam TH. Seismic response of interior RC beam-column joints upgraded with FRP sheets. I: Experimental study. J Compos Constr 2007; 11: 575-89.

[9] Parvin A, Wu S. Ply angle effect on fibre composite wrapped reinforced concrete beam-column connections under combined axial and cyclic loads. Compos Struct 2007; 82: 532-38.

[10] Alsayed SH, Al-Salloum YA, Almusallam TH, Siddiqui NA. Seismic response of FRP-upgraded exterior RC beam-column joints. J Compos Constr 2010; 14: 195-08. 
573 [11] Almusallam TH, Al-Salloum YA. Seismic response of interior RC beam-column joints upgraded with FRP sheets. II: Analysis and parametric study. J Compos Constr 2007; 11: 590-00.

[12] Tsonos AG. Effectiveness of CFRP jackets in post-earthquake and pre-earthquake retrofitting of beam-column subassemblages. Struct Eng Mechan 2007; 27: 393-08.

[13] Akguzel U, Pampanin S. Assessment and design procedure for the seismic retrofit of reinforced concrete beam-column joints using FRP composite materials. J Compos Constr 2012; 16: 21-34.

[14] Shrestha R, Smith ST, Samali B. Strengthening RC beam-column connections with FRP strips. Proc the Institution of Civil Engineers-Structures and Buildings 2009; 162: 323-34.

[15] Herwig A, Motavalli M. Axial behaviour of square reinforced concrete columns strengthened with lightweight concrete elements and unbonded GFRP wrapping. J Compos Constr 2012; 16: 747-52.

[16] Hadi MNS. Retrofitting of shear failed reinforced concrete beams. Compos Struct 2003; 62: 1-6.

[17] Hadi MNS, Pham T, Lei X. New method of strengthening reinforced concrete square columns by circularizing and wrapping with fibre-reinforced polymer or steel straps. J Compos Constr 2013; 17: 229-38.

[18] Le-Trung K, Lee J, Lee DH, Lee K, Woo S. Experimental study of RC beam-column joints strengthened using CFRP composites. Composites Part B 2010; 41: 76-85.

[19] Karayannis CG, Chalioris CE, Sirkelis GM. Local retrofit of exterior RC beamcolumn joints using thin RC jackets-an experimental study. Earthq Eng and Struct Dyn 2008; 37: 727-46. 
597 [20] Sezen H. Repair and strengthening of reinforced concrete beam-column joints with fibre-reinforced polymer composites. J Compos Constr 2012; 16: 499-06.

599

600

601

602

603

604

605

606

607

608

609

610

611

612

613

614

615

616

617

618

619

620

621

[21] AS1391. Metallic materials-tensile testing at ambient temperature. SAI Global database 2007.

[22] AS1012.09. Methods of testing concrete - determination of the compressive strength of concrete specimens. SAI Global database 1999.

[23] ACI 352R. Recommendations for design of beam-column joints in monolithic reinforced concrete structures. ACI-ASCE Joint Committee 352, American Concrete Institute, Farmington Hills, MI 2002.

[24] Quintero-Febres CG, Wight JK. Experimental study of reinforced concrete interior wide beam-column connections subjected to lateral loading. ACI Struct J 2001; 98: 572-82.

[25] ASTM D7565. Standard test method for determining tensile properties of fibre reinforced polymer matrix composites used for strengthening of civil structures. ASTM Database 2010.

[26] Tran TM, Matuszkiewicz B, Hadi MNS. Response of substandard reinforcing details T connections upgraded with concrete covers and CFRP. Pro $4^{\text {th }}$ Asia-Pacific Conf on FRP in Structures, Melbourne 2013.

[27] ASTM D3039. Standard test methods for tensile proper-ties of polymer matrix composite materials. ASTM Database 2008.

[28] Clyde C, Pantelides CP, Reaveley LD. Performance-based evaluation of reinforced concrete building exterior joints for seismic excitation. Earthq Spect 2000; 18: 44980.

[29] Pantelides CP, Hansen J, Nadauld J, Reaveley LD. Assessment of rc building exterior joints with substandard details. PEER Report No. 2002/18, University of Utah 2002. 
622 [30] Hwang SJ, Lee H J, Liao TF, Wang KC, Tsai HH. Role of hoops on shear strength of

623

624

625

626

627

628

629

630

631

632

633

634

635

636

637

638

639

640

641

642

643

644

645

646 reinforced concrete beam-column joints. ACI Struct J 2005; 102: 445-53.

[31] Ilki A, BedirhanogluI, Kumbasar N. Behaviour of FRP-retrofitted joints built with plain bars and low-strength concrete. J Compos Constr 2011; 15: 312-26.

[32] Lee HJ, Yu SY. Cyclic response of exterior beam-column joints with different anchorage methods. ACI Struct J 2009; 106: 329-39.

[33] AS3600-2009. Concrete structures. SAI Global database 2009.

[34] Priestley MJN. Displacement-based seismic assessment of reinforced concrete buildings. J Earthq Eng 1997; 1: 157-92.

[35] Bousselham A. State of research on seismic retrofit of RC beam-column joints with externally bonded FRP. J Compos Constr 2010; 14: 49-61.

[36] Allam KH. Analytical and experimental evaluation of seismic performance of interior RC beam-column joints strengthened with FRP composites. Thesis 2010, University of California, Irvine.

[37] Li B, Yiming W, Pan T-C. Seismic behaviour of non-seismically detailed interior beam-wide column joints - part I: Experimental results. ACI Struct J 2002; 99: 79102.

[38] Tsonos AG. Effectiveness of CFRP-jackets and RC-jackets in post-earthquake and pre-earthquake retrofitting of beam-column subassemblages. Eng Struct 2007; 30: 777-93. 
650

\section{Table 1}

Test results of CFRP

\begin{tabular}{ll}
\hline Measured properties & Results \\
\hline Maximum load (kN) & 35.4 \\
Maximum deflection (mm) & 2.69 \\
Coupon width (mm) & 25 \\
Gauge length (mm) & 150 \\
Maximum tensile force per unit with (N/mm) & 1417 \\
Maximum strain & 0.018 \\
Fiber elastic modulus (GPa) & 238 \\
\hline
\end{tabular}

651

652

653 
Fig. 1. Reinforcement details of Specimens TS and TR (all dimensions in mm)

Fig. 2. The formworks before casting

Fig. 3. (a) Test setup and (b) Cyclic loading history

Fig. 4. Position of strain gauges (all dimensions in mm)

Fig. 5. Retrofitting process (all dimensions in $\mathrm{mm}$ )

Fig. 6. Crack patterns of the joint before repairing

Fig. 7. The joint after filling epoxy into the cracks

Fig. 8. Load versus deflection responses hysteresis

Fig. 9. Response of the external CFRP layers during loading

Fig. 10. The final cracking patterns inside the CFRP jacket of Specimens TS

Fig. 11. The final cracking patterns inside the CFRP jacket of Specimens TR

Fig. 12. Shear load and stiffness comparison

Fig. 13. Dissipated energy comparison

Fig. 14. Sectional analysis of FRP strengthened RC beam 


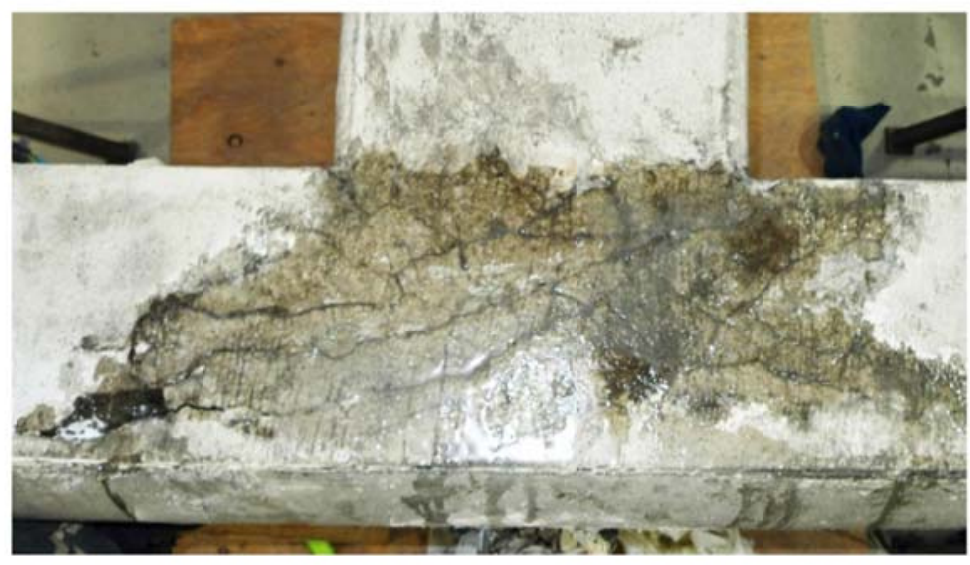

665 


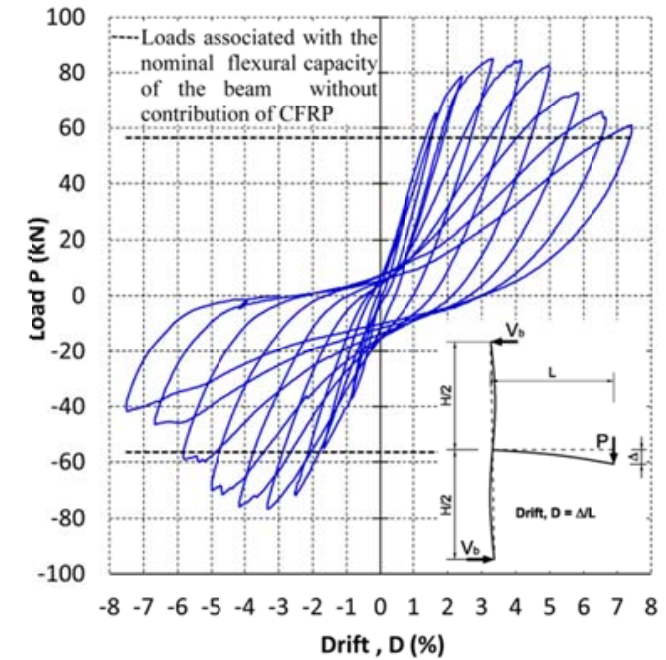

(a) Specimen TS

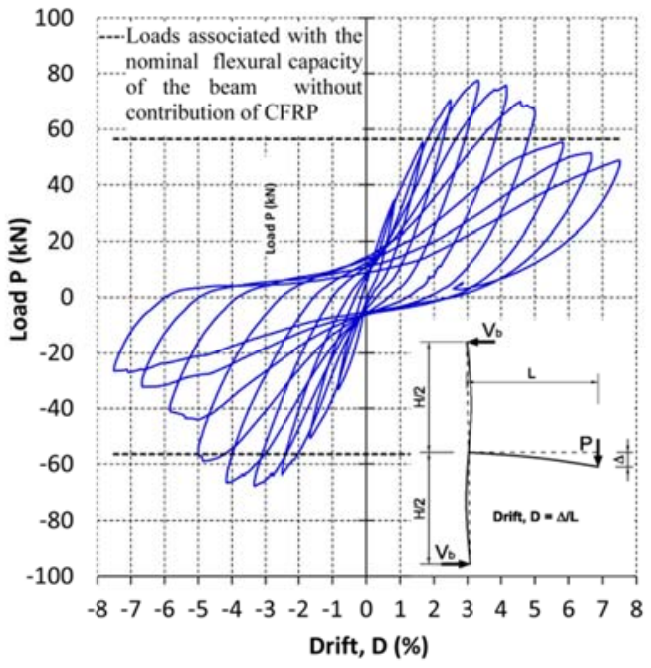

(b) Specimen TR

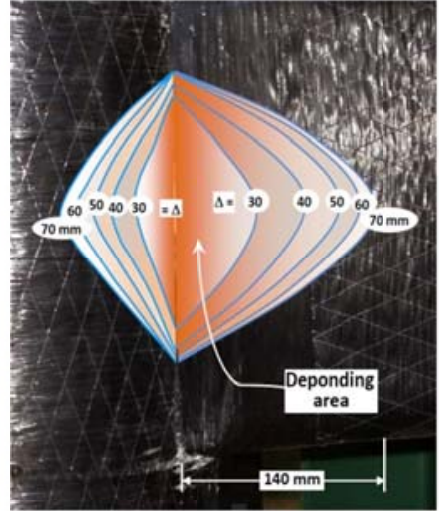

(a) Deponding area of CFRP at the end of the $3,4,5,6,7^{\text {th }}$ loading cycles

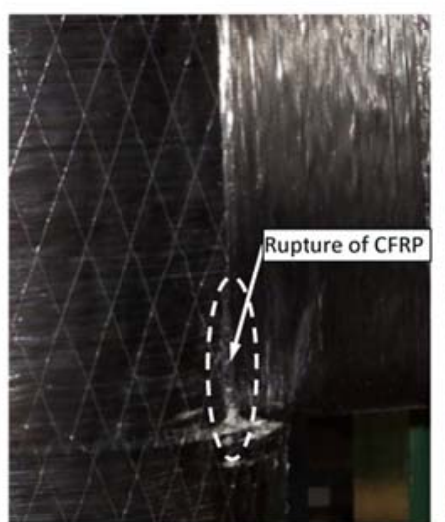

(b) Rupture of horizontal layers of CFRP at the end of the third loading cycle

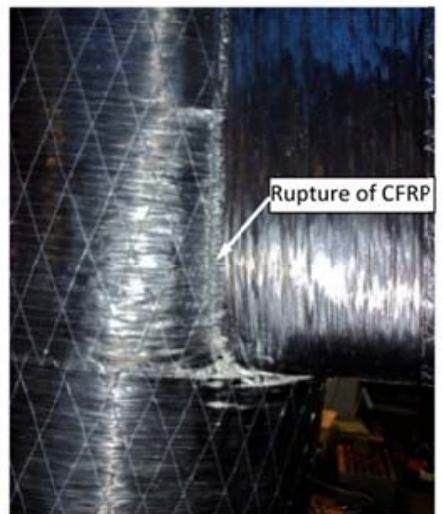

(c) Rupture of horizontal layers of CFRP at the end of the $7^{\text {th }}$ loading cycle 


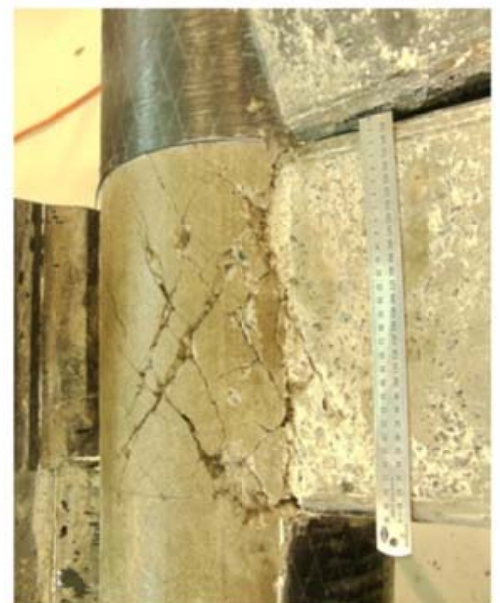

(a) The joint after air blasting

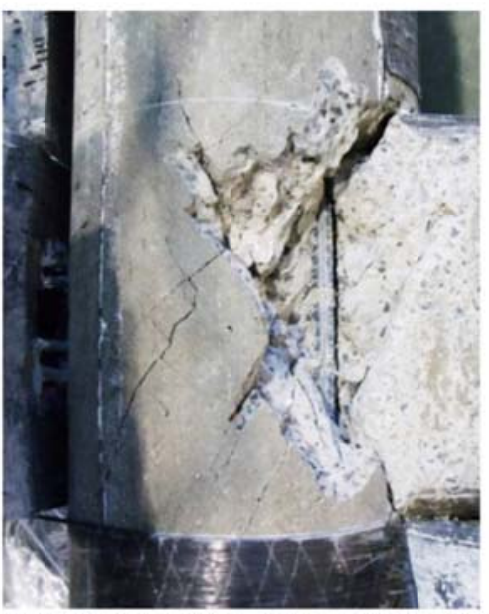

(c) The joint after removing crushing concrete fragments and air blasting

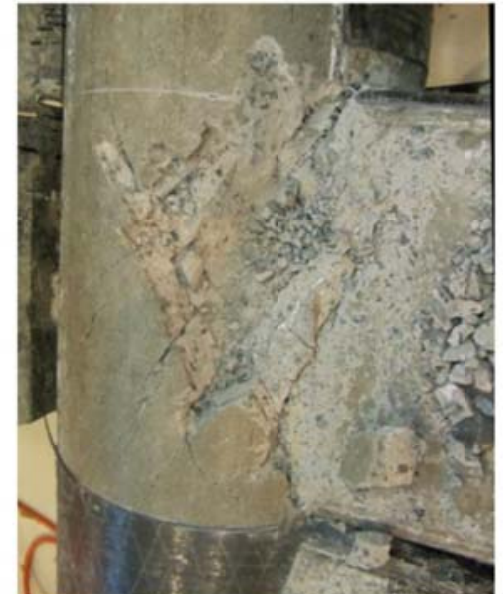

(b) The joint after manually removing crushing concrete fragments

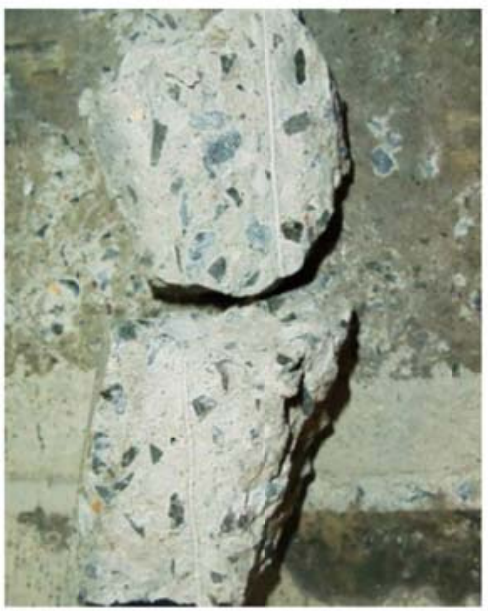

(d) The bond between the the glued and the existing concrete 


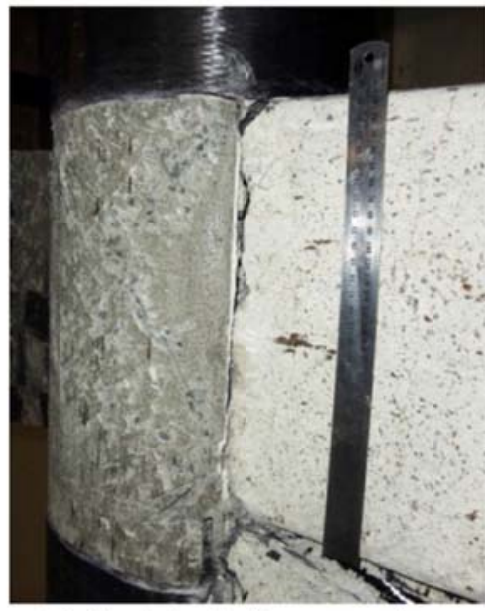

(a) The joint before removing crushing concrete

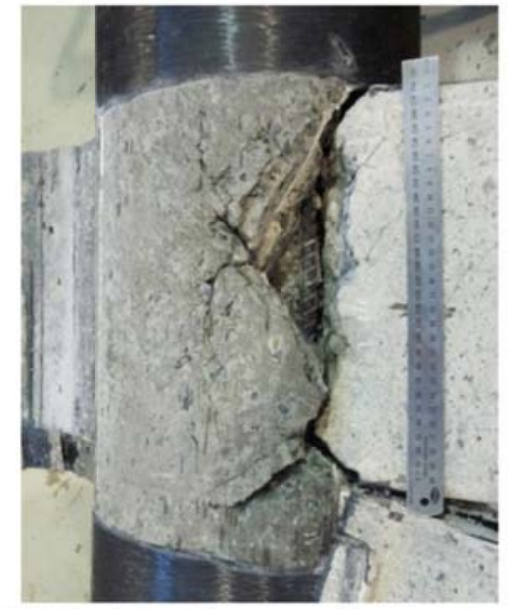

(b) The joint after manually removing crushing concrete fragments 


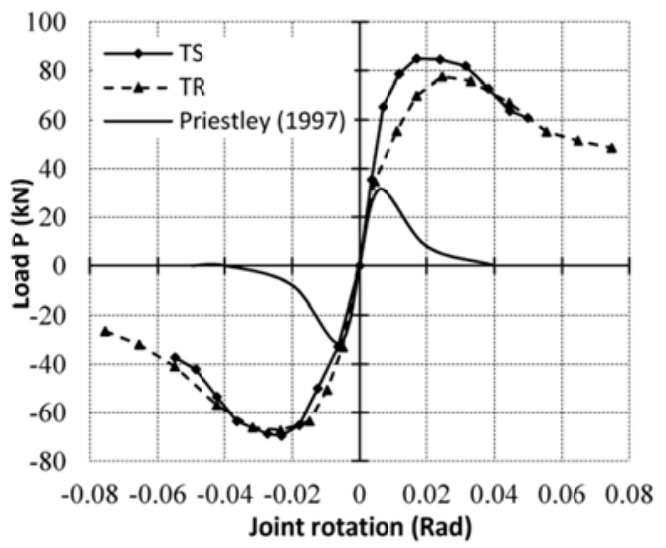

(a) Shear load versus joint rotation

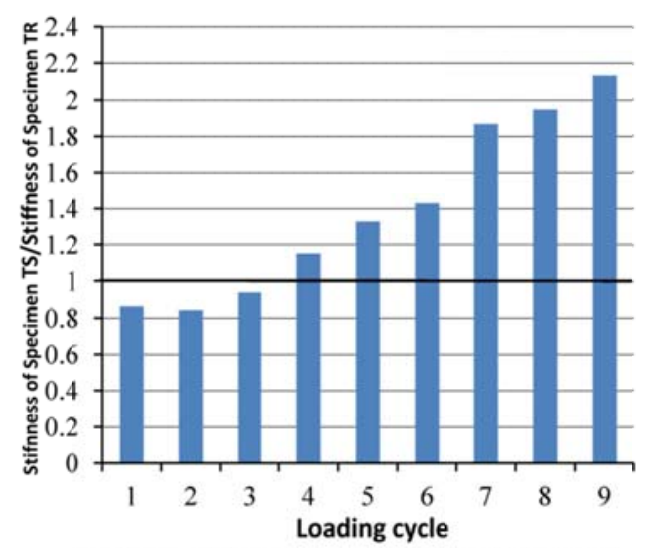

(b) Stiffness ratio between Specimens TS and TR 


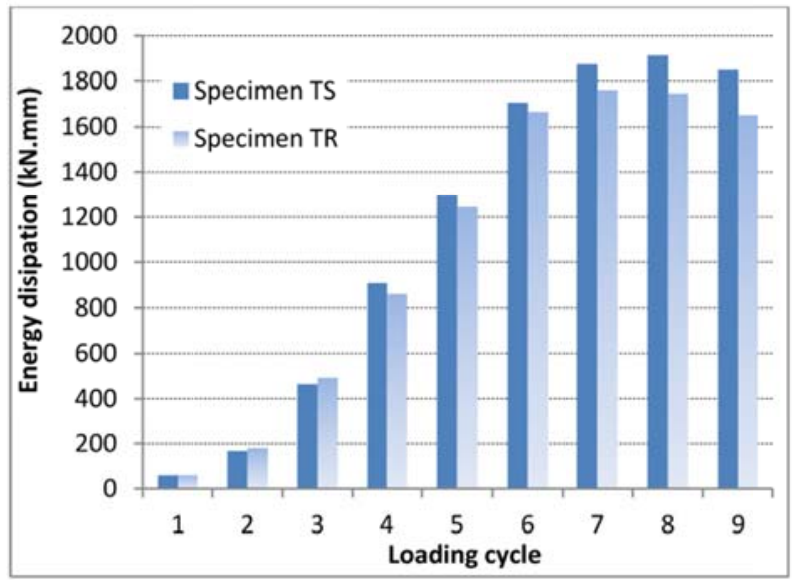

671 


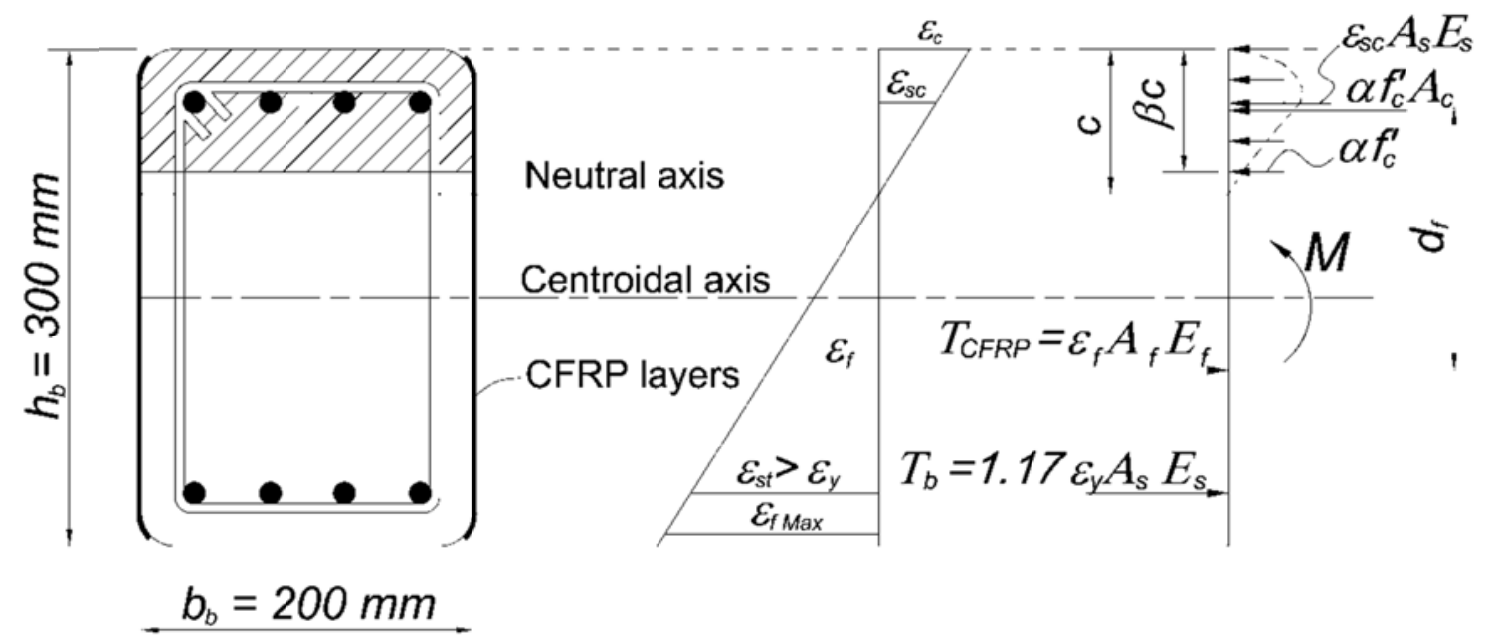




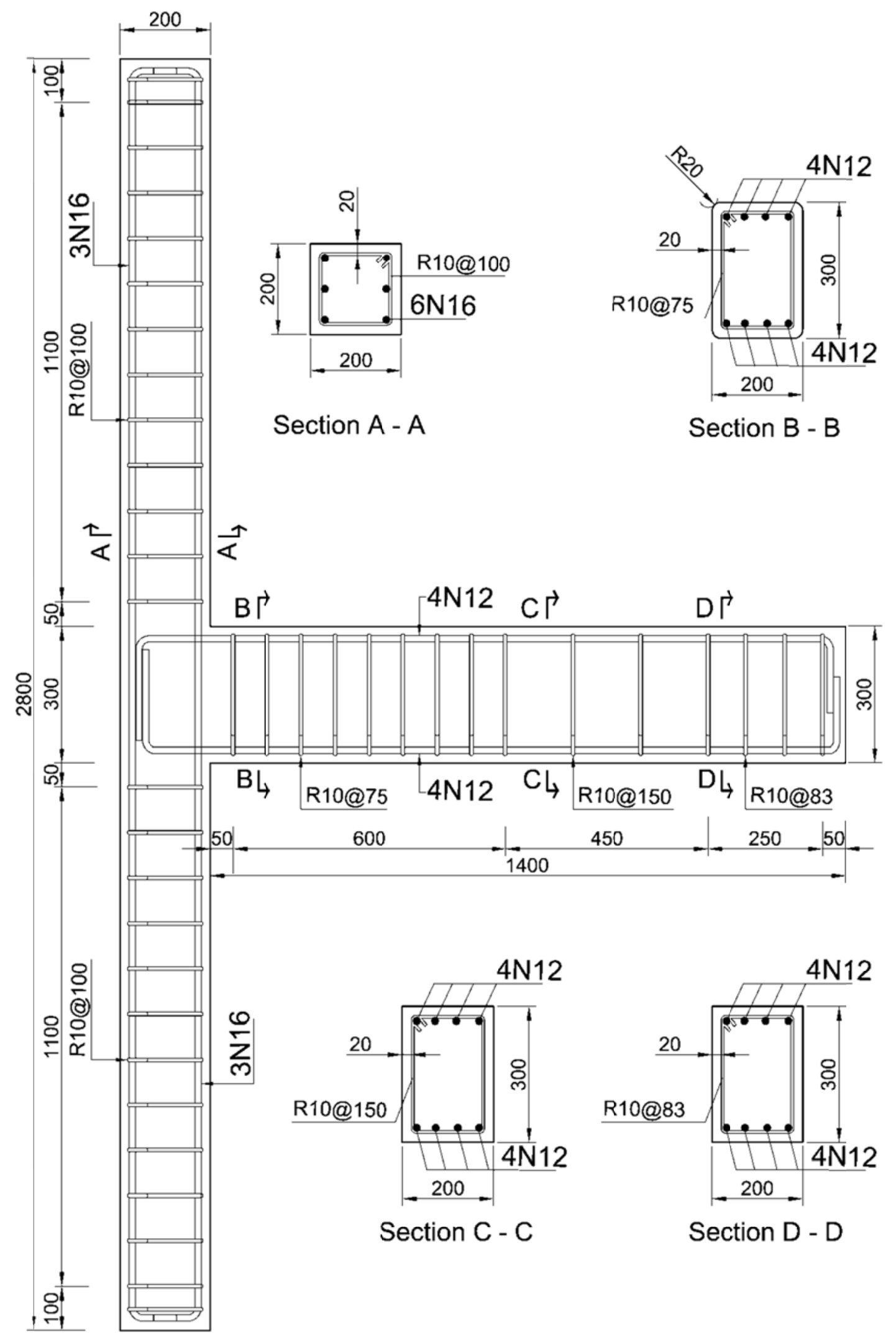

673 


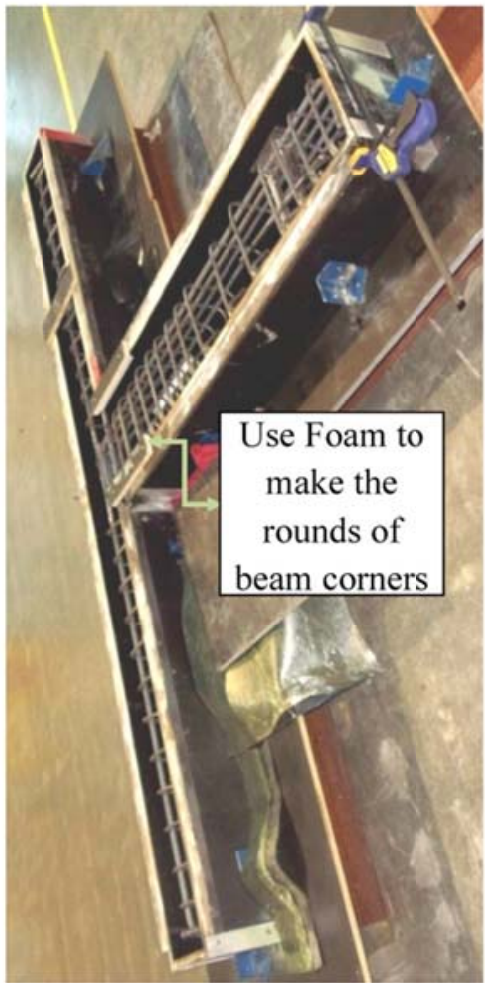

$\mathrm{T}$ connection formwork

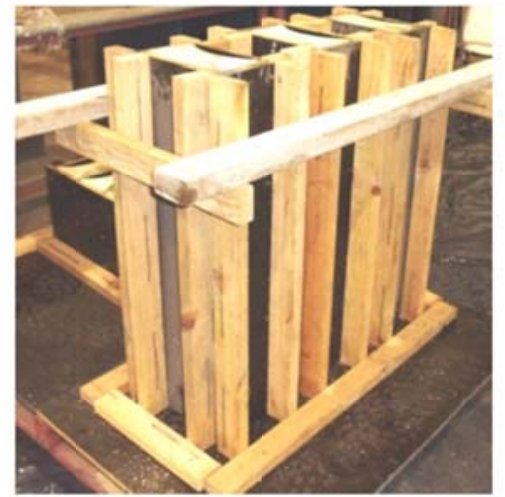

$900 \mathrm{~mm}$ length covers formwork

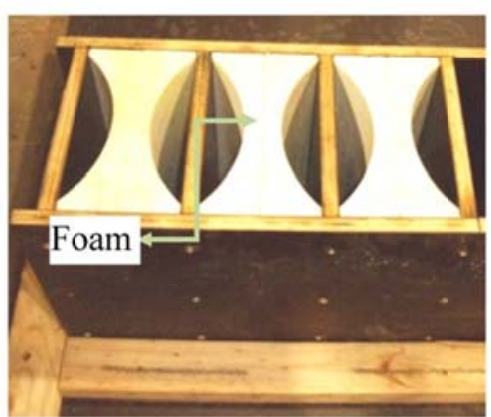

$300 \mathrm{~mm}$ length covers formwork 


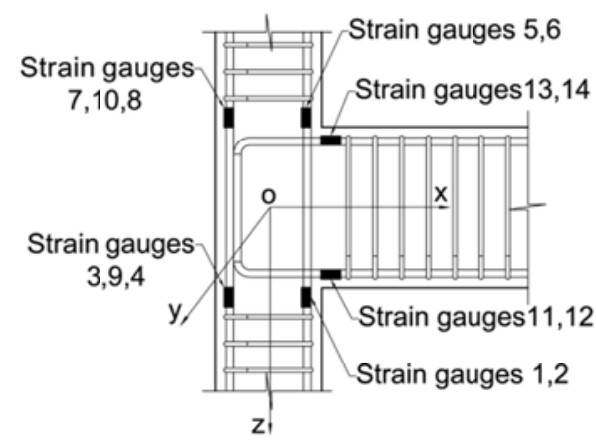

Position of strain gauges on steel reinforcement

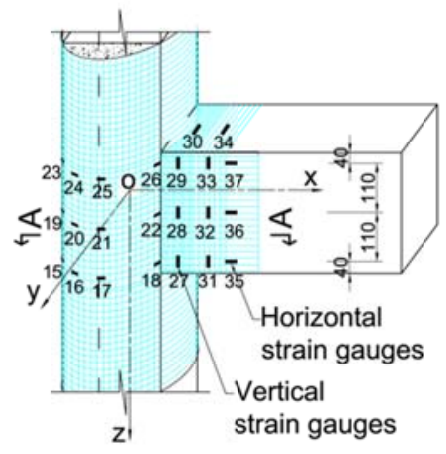

Position of strain gauges on external CFRP

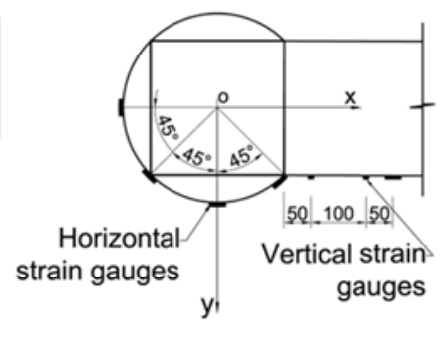

Section A - A

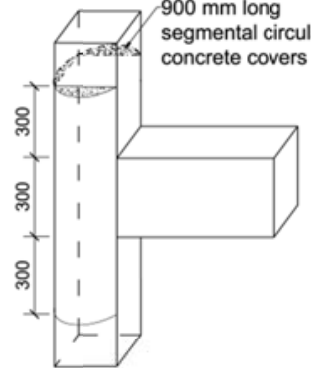

Step 1: Glue three $900 \mathrm{~mm}$ long concrete covers

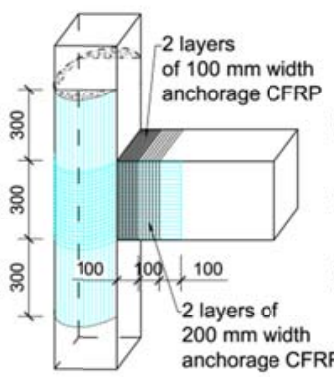

Step 4: Wrap layers of anchorage CFRP

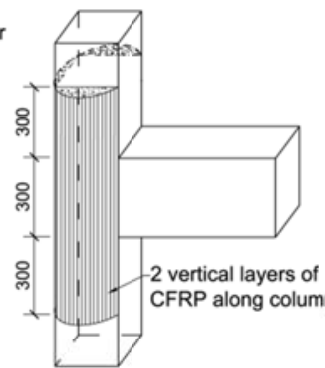

Step 2: Wrap 2 vertical layers of CFRP along column

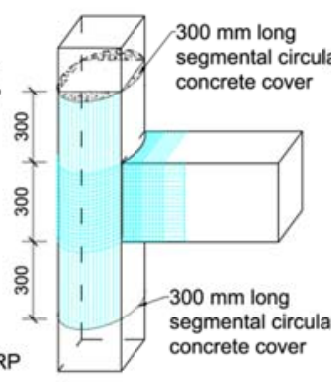

Step 5: Glue two 300mm long concrete covers
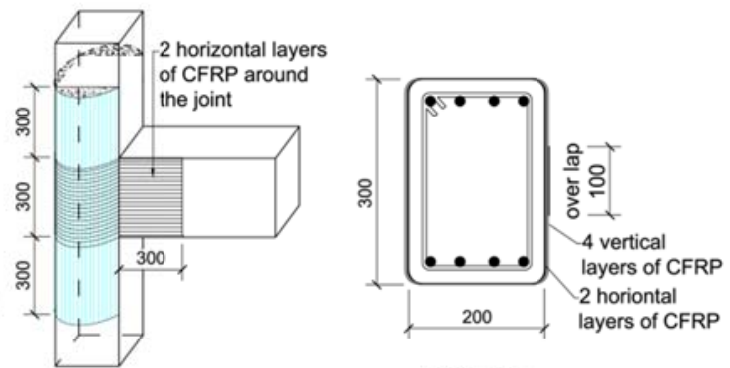

Step 3: Wrap 2 horizontal layers of CFRP around the joint
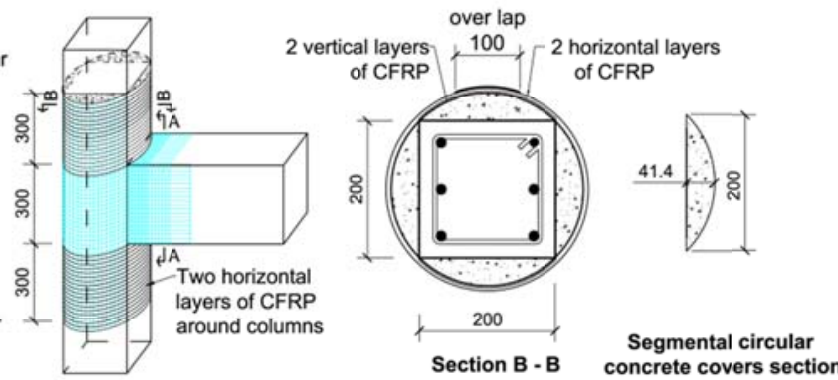

Step 6: Wrap horizontal layers of CFRP around column 


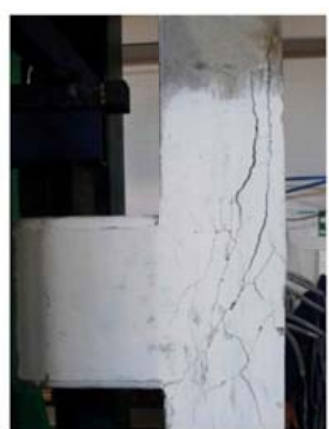

(a) Front face of the joint

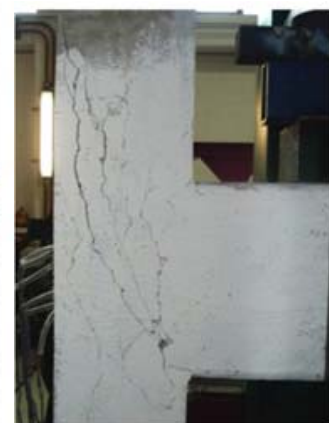

(b) Back face of the joint

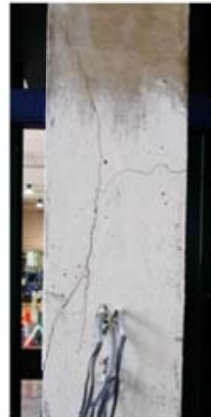

(c) Back of the column

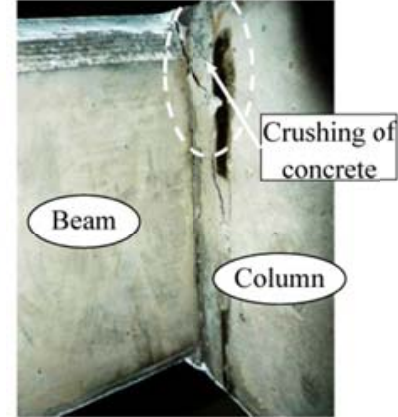

(d) Bottom corner of beamcolumn joint 